This a post-print version of an article published in Ethical Theory and Moral Practice,

DOI: $10.1007 / \mathrm{s} 10677-018-9937-\mathrm{z}$

\title{
Parental Justice and the Kids Pay View*
}

\author{
Erik Magnusson \\ Universitat Pompeu Fabra
}

\begin{abstract}
In a just society, who should be liable for the significant costs associated with creating and raising children? Patrick Tomlin has recently argued that children themselves may be liable on the grounds that they benefit from being raised into independent adults. This view, which Tomlin calls 'Kids Pay', depends on the more general principle that a beneficiary can incur an obligation to share in the cost of an essential benefit that the benefactor is responsible for her requiring. I argue in this paper that this principle is both generally false and particularly suspect in the kinds of cases that Tomlin needs it to be true, namely, cases in which a benefactor has created the need to be benefitted to satisfy a self-regarding interest in providing the benefit. In a nutshell, I argue that because parents (a) electively put their children into a needy circumstance for the purpose of (b) satisfying a self-regarding interest in meeting their children's needs, they lack a legitimate claim against their children to share in its associated costs.
\end{abstract}

Keywords: parental justice; Kids Pay; principle of fair play; benefit foisting; Patrick Tomlin

\section{INTRODUCTION}

Anyone who has undertaken the project of creating and raising a child will be all too familiar with the fact that kids are expensive. A recent report in the United Kingdom has found that the average cost of raising a child in that country from birth until the age of twenty-one is now in excess of $£ 229,251$, which averages out to approximately $£ 10,917$ per year, $£ 910$ per month, and $£ 30.00$ per day. For the typical twoparent family, this expenditure accounts for around $29 \%$ of annual household income; for single-parent families, it exceeds 54\% (Liverpool Victoria, 2015). ${ }^{1}$ And these, of course, are only the financial costs. In

\footnotetext{
${ }^{*}$ For helpful comments and discussion on previous drafts, I am grateful to Serena Olsaretti and Isabella Trifan. Research for this project was supported by the European Research Council (ERC) project on Justice and the Family: An Analysis of the Normative Significance of Procreation and Parenting in a Just Society (Grant number: 648610; grant acronym: Family Justice).

${ }^{1}$ Note that these figures are merely illustrative of the significant amount of resources that are typically devoted to childrearing - they do not by themselves tell us how much ought to be spent on childrearing.
} 
addition to a significant financial investment, prospective parents can also expect to invest an enormous amount of time and energy in the raising of their children, and to incur innumerable opportunity costs along the way. They can expect to routinely forgo their own interests in favour of the interests of their children, and to live their lives with less flexibility than non-parents in their society who are in similar financial circumstances.

From the perspective of justice, an important question concerns how the significant costs of procreation and parenting ought to be distributed throughout society. Should parents ${ }^{2}$ be responsible for paying the full cost of their childrearing projects, or should childrearing costs be shared in some way among parents and non-parents alike? To the extent that philosophers have considered this question, two sets of views have emerged, which, following Serena Olsaretti (2013, p. 229), we can label anti-cost-sharing and procost-sharing views, respectively (or anti-sharing and pro-sharing views, for short). According to anti-sharing views, the cost of creating and raising children should be borne primarily, if not entirely, by parents themselves. This set of views counts among its defenders responsibility-sensitive egalitarians, who see childrearing as a choice for which individuals ought to be held responsible (Casal, 1999; Casal and Williams, 2004; Clayton, 2006, pp. 67-70; Rakowski, 1991, pp. 150-154; Vallentyne, 2002). Assuming an initially just distribution of resources, these theorists reason that it would be unfair to diminish the resource share of non-parents for the sake of financing the expensive choices of parents - after all, it is parents who bring it about that there are children with costly needs to be met, so the responsibility for meeting those needs ought to fall primarily on them.

Proponents of pro-sharing views see things differently. While it is true that the costs of childrearing arise out of the voluntary ${ }^{3}$ choices of parents, focusing too narrowly on the origins of those costs distracts attention from the various ways in which non-parents benefit from parents' childrearing labour. For example, in societies with redistributive social welfare systems, non-parents benefit from the existence of a

\footnotetext{
${ }^{2}$ Unless otherwise noted, I use the term 'parent' in this paper to refer to procreative parents, or persons who are responsible for creating and raising other human beings.

${ }^{3}$ In this paper, I will assume for the sake of argument that the decision to create and raise a child is always fully voluntary.
} 
younger generation that can maintain the economic institutions they will depend on in old age (Folbre, 2001; George, 1987; Olsaretti, 2013). ${ }^{4}$ Moreover, if the value of our life projects is predicated on the assumption that others will live on after we die - as theorists like Samuel Scheffler (2013) have recently argued - they may also benefit from the contribution that parents make to the "collective afterlife." Proponents of pro-sharing views insist that because non-parents stand to benefit from others' childrearing labour in either or both of these ways, they have a fairness-based obligation to share in the cost of that labour by contributing to a cost-sharing scheme.

Until recently, pro-sharing arguments in the parental justice debate have largely been framed in forward-looking terms, focusing on the future benefits that non-parents will enjoy as a result of parents' childrearing labour. ${ }^{5}$ However, in a recent and engaging article, Patrick Tomlin (2015) has proposed a distinctively backward-looking ${ }^{6}$ version that focuses on the past benefits that non-parents have already enjoyed during their upbringing. This view calls attention to the fact that non-parents are not only the future beneficiaries of other people's childrearing labour, but are also the past beneficiaries of the childrearing labour of their own parents, and may on that basis have an obligation to pay some of those costs forward by contributing to a cost-sharing scheme. If sound, this backward-looking argument-which Tomlin calls 'Kids Pay' — has important implications for the debate on parental justice: not only would it provide an additional basis on which to share the costs of childrearing, and thus an additional basis on which to reject

\footnotetext{
${ }^{4}$ This is not to suggest that non-parents do not benefit in other ways from parents' childrearing labour in societies without redistributive welfare systems (e.g. from the existence of a workforce). I mention welfare states specifically only because they are a common focus of discussion in the parental justice literature. I am grateful to an anonymous reviewer for suggesting this clarification.

${ }^{5}$ Two notable exceptions include Anne Alstott's (2004) argument from autonomy and Paul Bou-Habib's (2013) argument from insurance.

${ }^{6}$ It should be noted that within the existing literature on parental justice, the terms 'forward-looking' and 'backward-looking' have sometimes been used differently than they are being used here. For example, Olsaretti (2013, pp. 237-238) uses the term 'forward-looking' in relation to pro-sharing views that justify cost-sharing on the grounds that it will incentivize citizens to have more children and thereby avoid demographic imbalance in the future, and the term 'backward-looking' in relation to pro-sharing views that justify cost-sharing on grounds of fairness. This is perhaps the more common usage, though for the purposes of this paper I will follow Tomlin (2015, p. 666) in using the term 'forward-looking' in relation to pro-sharing arguments that justify cost-sharing in virtue of benefits that non-parents will enjoy in the future, and 'backward-looking' in relation to pro-sharing arguments that justify cost-sharing in virtue of benefits that non-parents did enjoy during their childhood.
} 
strictly anti-sharing views, but it would also do so in a way that avoids important normative and empirical objections that have been raised against its forward-looking counterpart.

In this paper, I critically evaluate Tomlin's argument with a view to assessing its ability to deliver on these advantages. While there are numerous facets of Tomlin's argument that merit further discussion, I focus my attention on what I take to be his most interesting and important normative claim: that a beneficiary can incur an obligation to share in the cost of an essential benefit that the benefactor is responsible for her requiring. I argue that this claim is both generally false and particularly suspect in the kinds of cases that Tomlin needs it to be true, namely, cases in which a benefactor has created the need to be benefitted to satisfy a self-regarding interest in providing the benefit. In a nutshell, I argue that because parents (a) electively put their children into a needy circumstance for the purpose of (b) satisfying a self-regarding interest in meeting their children's needs, they lack a legitimate claim against their children to share in its associated costs.

The paper proceeds in three parts. In Part 1, I outline Kids Pay and its potential advantages over forward-looking pro-sharing views. In Part 2, I introduce the parental responsibility objection and clarify the challenge it presents to Tomlin's argument. Finally, in Part 3, I consider a possible response to this objection and explain why it fails.

\section{KIDS PAY}

Like its forward-looking counterpart, Tomlin's backward-looking argument begins with the principle of fair play, according to which we sometimes have an obligation to contribute to schemes or institutions from which we benefit. Building on H.L.A. Hart's (1955, p. 185) original formulation, John Rawls (1971, p. 112) describes the idea behind this principle in the following way:

...when a number of people engage in a mutually advantageous cooperative venture according to rules, and thus restrict their liberty in ways necessary to yield advantages for all, those who have submitted to these 
restrictions have a right to similar acquiescence on the part of those who have benefitted from their submission. We are not to benefit from the cooperative efforts of others without doing our fair share.

The principle of fair play is commonly applied to the production of non-excludable public goods, or goods that are either impossible or too costly to prevent non-contributors from enjoying. To take a stock example, imagine that a group of environmentalists routinely pick up litter on a commonly owned beach, thereby creating a public good (Casal, 1999, p. 365). As a result of their service, more people come to use the beach, and it soon becomes littered with garbage. The principle of fair play implies that when it comes time to clean the beach again, the environmentalists have a legitimate claim to assistance from the beachgoers who have enjoyed using it. After all, the environmentalists have benefitted everyone as a result of their service, and the beachgoers would be unfairly free riding on their efforts by enjoying the benefits without contributing to the costs.

Forward-looking arguments appeal to the principle of fair play to explain why it is unfair for adult non-parents to enjoy the benefits of parental labour without contributing to its costs, though Tomlin argues that a similar line of reasoning can also be directed toward children. If (a) we sometimes have an obligation to contribute when we have benefitted, and (b) children benefit from being raised, then it is possible that they too have a fairness-based obligation to share in the cost of that benefit. However, because children are unable to contribute to the cost of being raised ahead of time, this obligation would be discharged after the fact by contributing to a cost-sharing scheme upon reaching adulthood, the proceeds of which would then be paid forward to the next generation of parents. If sound, this argument suggests that non-parents are not only liable to share in the cost of childrearing in virtue of their status as the future beneficiaries of other people's childrearing labour, but also in virtue of their status as the past beneficiaries of the childrearing labour of their own parents.

The novelty of Tomlin's argument consists in applying the principle of fair play in a new way to support an additional basis of liability, though its success will depend on whether this application is an appropriate one. Two concerns immediately present themselves. First, in the Rawlsian formulation 
presented above, the principle of fair play is meant to govern the production of public goods by mutually advantageous cooperative ventures, though the benefit of an upbringing is better understood as a private good conferred by individuals. Does this affect the principle's applicability? Perhaps not necessarily. While many theorists limit the principle of fair play to the production of public goods by cooperative enterprises (Hart, 1955; Rawls, 1971; Simmons, 1979; Arneson, 1982; Klosko, 1987), others have suggested that this limitation is arbitrary and unnecessarily restrictive (McDermott, 2004, pp. 220-222). Imagine, for example, that your long-suffering roommate routinely cleans the kitchen in your apartment, and as a result, you and your friends regularly use it to cook elaborate meals. When it comes time to clean the kitchen again, it seems like you and your friends have the same moral reason to contribute as the beachgoers in the previous example, suggesting that fair play obligations can also arise from the enjoyment of private benefits conferred by individuals.

However, a second and more troubling concern is that, unlike the beachgoers or your culinary group, who can choose whether to enjoy the beach or the kitchen, a child cannot choose whether to enjoy the benefit that gives rise to fair play obligations. ${ }^{7}$ Rather, the benefit of an upbringing - and the corresponding obligation to share in its costs - is necessarily foisted on children without their consent. This is concerning because fair play obligations are not generally thought to arise from private benefits that have been foisted on others (Arneson, 1982, pp. 617-623). To borrow an example from Robert Nozick (1971, p. 95), one cannot simply toss books into other people's windows as a form of exercise and then demand that they contribute toward the cost of this bizarre workout. But if fair play obligations do not generally arise from private benefits that have been foisted on others, then why should children be liable to share in the cost of their upbringing?

\footnotetext{
${ }^{7}$ Not all theorists agree that voluntarily accepting a benefit is necessary for the generation of fair play obligations. Klosko (1987, p. 247) and Arneson (1982, pp. 620-623) both argue that simply receiving a benefit can give rise to fair play obligations so long as the benefit in question is of a certain type, e.g. a public good that is necessary for a minimally decent life and which all individuals can be presumed to want. Others, however, argue that there is a morally relevant distinction between passively receiving and actively accepting a benefit, and that fair play obligations can only arise from benefits that have been actively accepted (Simmons, 1979, pp. 319-333; Hart, 1955, p. 185; Rawls, 1971, pp. 111-112).
} 
Tomlin has an answer to this question, and it forms the centrepiece of his argument. According to Tomlin (2015, p. 669), benefit foisting - by which he means the non-consensual provision of private benefits and subsequent demanding of repayment — can be justified so long as the following conditions obtain:

(1) the benefit in question is necessary for an acceptable life;

(2) the recipient is not available to provide their consent; and

(3) it is not possible or reasonable to wait for them to become so available.

To illustrate the plausibility of these conditions, Tomlin provides the following type of example:

Mountain Rescue: Alice is a retired helicopter pilot living in a remote cabin in the Canadian Rockies. One day she receives a weather report informing her that a massive avalanche has blocked a key mountain pass on a popular hiking trail, trapping a group of hikers she knows to be hiking there. The only way to get them out is for Alice to use her helicopter to airlift them to safety, though operating the helicopter is extremely expensive. Alice has no way of communicating with the group, so she cannot ask them if they are willing to pay the cost of a rescue; however, she cannot possibly wait to ask them either, as they will soon freeze unless they are rescued. Knowing that time is of the essence, Alice hops in her helicopter, rescues the group, and then hands each hiker an invoice for a portion of the cost. ${ }^{8}$

In this case, a private benefit has been foisted on the hikers, though unlike the beneficiaries of Nozick's book tosser, it does not seem unreasonable to hold them liable for part of the cost. This, Tomlin suggests, is due both to the essential nature of the benefit as well as the special circumstances in which it is provided:

\footnotetext{
${ }^{8}$ This is my own version of Tomlin's (2015, p. 668) Matrix case. I have chosen to replace the original case because (a) I lack the requisite sci-fi knowledge to appropriately modify Matrix in the sections to follow, and (b) I think that the plausibility of Tomlin's conditions is better illustrated through an example that more closely resembles real life.
} 
(1) the good of a rescue was necessary for an acceptable life; (2) the hikers were not available to provide their consent; and (3) it was not possible or reasonable for them to wait to become so available. Thus, insofar as someone must bear the cost of the rescue, the primary beneficiaries seem like appropriate candidates.

Tomlin extends the same reasoning to the case of childrearing, as it too exhibits the three conditions that justify benefit foisting in cases like Mountain Rescue: (1) the benefit of an upbringing is necessary for an acceptable life; (2) a child is not yet an agent, and is therefore unable to offer their consent; and (3) it is not possible to wait for them to become so available, as the benefit of an upbringing is required for them to become a moral agent. Thus, Tomlin (2015, p. 669) concludes that two kinds of benefits can be justifiably foisted on children:

Since [a child's] liability to contribute towards foisted benefits is due to a combination of her lack of agency and the essential nature of the good, she can justly be asked to contribute towards (a) goods essential for reaching full agency, and (b) goods that are not essential for reaching full agency, but which are essential for a minimally decent life and which can only be reasonably provided prior to full agency. All other essential goods that could be provided prior to full moral agency, but which could reasonably be provided later, are not foistable, as it would be reasonable to wait to seek consent.

As an argument in favour of sharing the costs of childrearing, Kids Pay has two potential advantages over forward-looking pro-sharing views. First, because it derives a cost-sharing obligation from benefits that non-parents have already enjoyed during their upbringing, Kids Pay avoids the empirical objection that childrearing labour may not produce benefits in the future, either because it will fail to produce economically productive citizens, or because it will contribute to collective harms like overpopulation or environmental degradation (Casal, 1999, 370-373). Since children are normally made better off as a result of being raised into independent adults, their status as beneficiaries may be less controversial on Kids Pay. Second, because childrearing labour is performed with the intention of raising children into independent adults, Kids 
Pay also avoids an important normative objection that has been raised against forward-looking pro-sharing views, namely, that because parents do not intend to create benefits for non-parents, they lack a legitimate claim to their cost-sharing contributions (Casal, 1999, pp. 367-368; Casal and Williams, 2004, pp. 156160). The relevance of this objection is disputed in the literature on parental justice (see, for example, Olsaretti, 2013, pp. 239-247), though Kids Pay has the advantage of simply avoiding it altogether.

Despite these advantages, however, Kids Pay faces challenges of its own, several of which have to do with the implications of the argument. For example, given that the benefit of an upbringing is a private benefit conferred by one's parents, it is not clear why the corresponding obligation is an obligation to contribute to a cost-sharing scheme, rather than, say, a reciprocal obligation to care for one's parents in old age. Considering both the nature of the benefit and the context in which it is provided, it seems like Tomlin's argument might be more appropriately framed as an account of filial obligation. Moreover, even if the corresponding obligation is an obligation to contribute to a cost-sharing scheme, there are questions about how such a scheme would work in practice. For example, must parents simultaneously pay for their own upbringing and their children's upbringing at the same time? Must children pay the full cost of their upbringing regardless of how efficient or inefficient their parents are in meeting their needs? And how should we respond to the concern that the transactional nature of such a scheme might detract from the valuable features of the parent-child relationship? ${ }^{9}$ These are all important questions that merit further consideration. However, in what follows, I will set aside concerns about the implications of Tomlin's argument and focus on what I take to be a more central objection to the argument itself: the parental responsibility objection.

\footnotetext{
${ }^{9}$ Tomlin $(2015,677)$ fully acknowledges the problems facing the implementation of his scheme and flags potential responses to them in $\mathrm{n}$. 27. I mention them here only as examples of the types of questions that must be addressed before Kids Pay can be accepted as a practicable view.
} 


\section{THE PARENTAL RESPONSIBILITY OBJECTION}

Tomlin's argument for Kids Pay is a parallel case argument, and as such, has the following general structure. First, it accepts a normative claim as appropriate in a given domain. Second, it identifies certain features of that domain in light of which the normative claim is justified. Third, it claims that those justifying features are also present in some other domain. Finally, it concludes that the normative claim applies in that other domain as well (Clayton, 2006, p. 93). When we plug Tomlin's specific claims into this general formula, we get the following argument:

(i) benefit foisting is justified in cases like Mountain Rescue;

(ii) its justification is due to the presence of conditions (1)-(3);

(iii) conditions (1)-(3) are also present in the case of childrearing; therefore,

(iv) parents are justified in foisting the benefit of an upbringing on children and demanding repayment later.

In order for this argument to succeed, the two cases must be sufficiently analogous to warrant extending the normative claim from the first case to the second case. However, as Tomlin (2015, pp. 671-672) himself acknowledges, there is an important disanalogy between the two cases that seems to tell against the proposed extension: whereas no one is responsible for the hikers' need to be rescued in the case of Mountain Rescue, there are identifiable persons responsible for a child's need to be raised. Moreover, these are the same persons who, in Tomlin's view, have a fairness-based claim against their children for the cost of meeting that need. Does the additional element of parental responsibility make a difference to children's liability?

According to Tomlin (2015, p. 671), our answer to this question will depend on how we answer "some very difficult questions about what it is that parents $d o$ to their children when they create them." If parents harm their children by creating them, then their claim to cost-sharing is severely undermined, as the costs associated with raising a child look more like something parents owe their children by way of 
compensation. However, if parents benefit their children by creating them, then their claim to cost-sharing is more plausible, as the costs are then incurred in the service of providing their children with a valuable good. Tomlin (2015, p. 671) illustrates these two possibilities with the following pair of cases:

Bart Harms Lisa: Bart intentionally and wrongfully knocks out Lisa and she falls into a coma. As a result, she requires expensive medical care.

Bart Saves Lisa: Lisa is drowning, and no one is responsible for her being in this situation. Saving her is so dangerous that no one is obligated to do so. Bart dives in, nevertheless, to save her. Once on the bank of the river, Lisa requires essential and expensive medical treatment.

In both of these cases, Bart is responsible for putting Lisa in a position where she must be provided with an essential and expensive good, yet his liability to assume the costs of that good appears to be different in each case: while he is clearly liable to pay the full cost of Lisa's medical treatment in Bart Harms Lisa, it is not clear that he is liable to pay any of the cost of her treatment in Bart Saves Lisa. Thus, Tomlin concludes that his argument succeeds so long as we think that parents are more like Bart in Bart Saves Lisa than in Bart Harms Lisa. More specifically, he believes that his argument succeeds so long as we do not believe that parents harm their children by creating them in such a way that they owe them compensation.

I will explain in the following section why Tomlin's argument fails even if we grant that parents benefit their children by creating them, though before doing so, it is first necessary to point out two major problems with his strategy for addressing the worry about parental responsibility. The first problem is that the case of Bart Saves Lisa is disanalogous to the case of procreative parenting in at least three important ways. First, while Lisa will die if Bart does not save her, no one will be made worse off if a set of parents do not procreate - thus, there is a Lisa-centered justification for the creation of her need for medical treatment that does not apply in the case of procreation. Second, while Bart is responsible for Lisa's need for medical treatment in only a loose sense, having by happenstance come across her in a state of distress, a 
child's need to be raised is the direct and foreseeable result of their parent's decision to procreate. Finally, while Bart's motivation for saving Lisa is entirely disconnected from the care she will later require, a prospective parent's motivation for creating a child is intimately connected to the care that the child will later require - for most prospective parents, the whole point of creating a child is to engage in the project of caring for her. Given these differences, we are not warranted in drawing any conclusions about a child's liability to share in the cost of their upbringing from Bart's liability to share in the cost of Lisa's medical treatment, as the two cases are not analogous in the relevant ways. A more analogous Simpsons-themed case would be one in which Bart knocked Lisa unconscious to satisfy a self-regarding interest in performing an operation that provided her with an overall benefit (e.g. increased intelligence), though I suspect that most people's intuitions about Lisa's liability to share in the cost of this type of benefit are likely to be very different than in Bart Saves Lisa (cf. Shiffrin, 1999, 127).

The second major problem with Tomlin's response is methodological. Tomlin's strategy for addressing the parental responsibility objection is to come up with a new case in which the benefactor's responsibility for the need to be benefitted does not relieve the beneficiary of her liability for costs. He does not consider, however, how the inclusion of this condition would affect his original example, which, in the context of his parallel case argument, provides the basis for thinking that benefit foisting is justified in the first place. This is a significant omission, for if it turned out that conditions (1)-(3) did not support benefit foisting in a modified original case in which the benefactor is responsible for the beneficiary's need to be benefitted, then we would have no initial reason for thinking that benefit foisting is justified in the case of childrearing.

Given the structure of Tomlin's argument, the best way to assess the relevance of parental responsibility for a child's cost-sharing liability is to consider whether liability would still accrue to the beneficiaries of Mountain Rescue in a modified case in which the benefactor was responsible for their need to be benefitted. Consider, then, the following modification: 
Mountain Rescue II: As a central component of his conception of the good, Alan, another retired helicopter pilot, desires to play a heroic role in the lives of others by rescuing them from a dangerous situation. He knows that a group of hikers are travelling on a popular hiking trail and will require access to a key mountain pass in order to complete their journey. Thus, before the group reaches the mountain pass, Alan detonates an explosive device he had previously planted there, triggering an avalanche and thereby trapping the hikers. The only way to get them out is for Alan to use his helicopter to airlift them to safety, though operating the helicopter is extremely expensive. Alan has no way of communicating with the group, so he cannot ask them if they are willing to pay the cost of a rescue; however, he cannot possibly wait to ask them either, as they will soon freeze unless they are rescued. Knowing that time is of the essence, Alan hops in his helicopter, rescues the group, and then hands each hiker an invoice for a portion of the cost.

Unlike the original Mountain Rescue, Mountain Rescue II shares two salient features of the standard cases of procreative parenting under consideration. First, and most importantly, the benefactor is responsible for the beneficiary's need to be provided with an essential benefit (call this the responsibility criterion). Just as procreative parents are responsible for their child's need to be raised, so too is Alan responsible for the hikers' need to be rescued. Had he not acted as he did, there would be no need to perform a rescue, and hence no need to incur the associated costs. Second, though perhaps less importantly, the benefactor has created the need to be benefitted to satisfy a self-regarding interest in providing the benefit (call this the self-interest criterion). Just as procreative parents typically create children in order to satisfy a personal interest in raising them, so too does Alan imperil the hikers in order to satisfy a personal interest in conducting a rescue. A case that satisfies these criteria is the type of case we need to consider in order to truly test the plausibility of Tomlin's argument. After all, we are not merely considering children's liability to share in the cost of a certain type of benefit provided in a certain type of situation, but rather their liability to share in the cost of a certain type of benefit provided in a certain type of situation that was deliberately created by the benefactor to satisfy a self-regarding interest in providing the benefit. 
Once we understand that this is the relevant type of test case, we can see that Tomlin's argument runs into one of two major problems, both of which — if sound - are sufficient to show that his argument fails. The first problem is that it is unclear whether a case that satisfies the responsibility criterion can ever meet Tomlin's own conditions for permissible benefit foisting, as condition (1) - the benefit's being necessary for an acceptable life — does not seem to apply in the relevant way. On a standard counterfactual interpretation, a person benefits from an act when their situation is improved relative to a counterfactual scenario in which the act was not performed. It follows on this view that a person essentially benefits from an act when their situation is improved in an essential way (e.g. with respect to the satisfaction of their basic interests) relative to a counterfactual scenario in which the act was not performed. This counterfactual test is clearly satisfied in the original Mountain Rescue, for Alice's act of conducting a rescue was in fact essential for the hikers to live acceptable lives: had she not conducted the rescue and left them stranded on the mountain, they would have been gravely worse off with respect to their basic interests. It is less clear, however, whether this counterfactual test is satisfied in the modified case of Mountain Rescue II. If we focus narrowly on Alan's rescue effort, it appears as though the hikers have essentially benefitted, as they are better off with respect to their basic interests than they otherwise would have been had Alan left them stranded on the mountain. But this appearance is deceiving: Alan's 'act' not only includes rescuing the hikers, but also imperilling them as well. And once we take this more expansive view of the act in question, we can see that no essential benefit has actually been delivered, for had Alan not imperilled and then rescued the hikers, they would have been no worse off with respect to their basic interests.

Parallel reasoning applies in the structurally analogous case of procreative parenting. If we focus narrowly on the provision of an upbringing, it appears as though children essentially benefit as a result of their parents' actions, as they are better off with respect to their basic interests than they otherwise would have been had they not been provided with an upbringing. But the relevant act on the part of parents also includes bringing their children into a state where they need to be raised. And once take this more expansive view of the act in question, we see again that no essential benefit has been delivered, for had the parents not chosen to create and then raise a child, no one would have been worse off with respect to their basic 
interests, as the child would not then have existed. ${ }^{10}$ There is a more general point underlying these specific instantiations: if the benefactor is responsible for creating the beneficiary's need to be provided with an essential benefit, then it can never be true that the provision of that benefit is essential at the relevant moment, i.e. prior to the benefactor's act-set being performed, and thus it can never be true that condition (1) obtains in cases of benefit foisting that satisfy the responsibility criterion.

If this reasoning is sound, it is sufficient to show that Tomlin's argument fails, for it demonstrates that conditions (1)-(3) do not in fact support the judgment that parents may permissibly foist the benefit of an upbringing on children they bring into existence. Even if I am mistaken, however, and condition (1) can apply in cases of benefit foisting that satisfy the responsibility criterion, a second and potentially more significant problem is that the presence of conditions (1)-(3) does not seem sufficient to establish liability on the part of the beneficiary, particularly when the self-interest criterion is also satisfied. Suppose for the sake of argument that conditions (1)-(3) are in fact satisfied in Mountain Rescue II, as (1) the benefit of a rescue is necessary for an acceptable life, (2) the hikers are not available to provide their consent, and (3) it is not possible or reasonable for them to wait to become so available. Even if this is true, the fact that Alan is responsible for the hikers' need to be rescued completely undermines the case for a fairness-based obligation to share in the cost of the rescue. While the hikers have in one sense benefitted from Alan's rescue, they have only benefitted relative to a scenario that he put them into for self-interested reasons: the hikers needed to be rescued because Alan chose to imperil them, and Alan chose to imperil them to satisfy a self-regarding interest in conducting a rescue. It seems clear, then, that he would have no legitimate complaint if the hikers refused to pay their bills. When presented with their invoices, the hikers might reasonably point out that if he was not willing to assume the full cost of satisfying his interest, he could have easily avoided it by not imperilling them - they would have been no worse off. However, having electively put them in a position where they require an expensive and essential good, he is at the very least obligated to

\footnotetext{
${ }^{10}$ Tomlin would likely point out that this argument assumes — contentiously — that existence itself is not beneficial. I will explain in the following section why his argument fails even if we assume for the sake of argument that we benefit children by bringing them into existence.
} 
provide them with that good and to assume the cost of its provision, particularly considering that he stands to benefit personally from providing it.

If this type of response is justified, it shows that the presence of conditions (1)-(3) is not sufficient to justify benefit foisting in cases that truly resemble childrearing, that is, cases in which (a) the benefactor is responsible for the beneficiary's need to be provided with an essential benefit, and (b) the benefactor has created that need in order to satisfy a self-regarding interest in providing the benefit. Of course, one might wonder whether (b) is in fact necessary in order to reach this conclusion, as we can imagine cases in which cost-sharing liability is precluded solely on the basis of (a). ${ }^{11}$ Imagine, for example, that Alan is ringing in the New Year with a fireworks display when a damaged firework shoots waywardly into a mountain side and triggers an avalanche, thereby trapping a group of hikers who he must then rescue. Even if Alan did not intend to imperil the hikers, and is in fact burdened by having to rescue them, we still might think that he is responsible for bearing the full cost of a rescue in virtue of his responsibility for their need to be rescued - in this sense, satisfaction of the responsibility criterion might alone be sufficient to preclude costsharing liability on the part of the beneficiary. ${ }^{12}$ However, even if we hold Alan liable in this modified case, the absence of the self-interest criterion makes an important moral difference to our evaluative attitudes toward him as well as his moral standing to complain. When Alan's liability is the result of bad moral luck, we might feel a certain degree of sympathy for his situation even if we think that, in the end, he should ultimately be held responsible for the consequences of his actions. However, no such sympathy arises when he has brought the situation about deliberately for self-interested reasons. In this case, the appropriate reaction to Alan's circumstance is the one expressed by the hikers in the preceding paragraph: if he was not willing to assume the full cost of satisfying his interest in conducting a rescue, he could have easily avoided

\footnotetext{
${ }^{11}$ I am grateful to Isabella Trifan and an anonymous reviewer for encouraging me to clarify the relevance of the selfinterest criterion for my argument in this section.

${ }^{12}$ I assume that some degree of moral (as opposed to strictly causal) responsibility can be attributed to Alan in this case in virtue of the inherent risks associated with setting off explosive devices, though as Olsaretti (2009, p. 167) points out, whether we think this translates into a responsibility to bear the full cost of rescuing the hikers will turn on a substantive 'principle of stakes', or 'an account of what consequences can justifiably be attached to features that are appropriate grounds of responsibility." It is possible to defend an alternative principle of stakes that would not recommend that Alan be held liable for the full cost of rescuing the hikers.
} 
it by not imperilling the hikers in the first place. In this sense, while satisfaction of the self-interest criterion is not strictly necessary to preclude cost-sharing liability on the part of a beneficiary, it is what we might think of as an aggravating factor, diminishing the strength of the complaint that the benefactor can raise about having to bear the full cost of providing an essential benefit.

In the case of procreative parenting, this supports a similar asymmetrical judgment. When a set of parents have brought a child into existence unintentionally — as a result of, say, contraceptive failure followed by the unavailability of a safe abortion —we might respond sympathetically to their complaints about having to bear the full cost of the child's upbringing, even if we think that, in the end, they should ultimately be held liable. ${ }^{13}$ However, no such response is warranted in cases where a set of parents have deliberately created a child to satisfy a personal interest in childrearing. In this type of case, we should understand any complaint on the part of parents as expressing an unreasonable wish: that they should get to pursue the course of action that best satisfies their own interests but without having to incur its full associated costs.

If the preceding arguments are sound, then Tomlin's parallel case argument for Kids Pay does not succeed, as the cases are not sufficiently analogous to warrant extending the normative claim from the first case to the second case, and appropriately modifying the first case to resemble the second case has the effect of debunking the normative claim in question. We ought, then, to endorse the following modification:

(i) benefit foisting is not justified in cases like Mountain Rescue II;

(ii) its lack of justification is due to the fact that the benefactor is responsible for the beneficiaries' need to be provided with an essential benefit;

(iii) parents are responsible for their children's need to be raised; therefore,

\footnotetext{
${ }^{13}$ I do not mean to endorse the view that unintentional parents should always be held liable for the full cost of raising their children, only that their lack of self-interested motivation in creating the child makes an important difference to our evaluative attitudes toward them and their moral standing to complain. If we endorse any of the existing arguments for socializing the costs of childrearing - including the arguments from fairness, autonomy, or insurance - then we may not think that they should be liable for the full cost, even if we agree that children themselves cannot be liable qua beneficiaries.
} 
(iv) parents are not justified in foisting the benefit of an upbringing on children and then demanding repayment later.

\section{THE HARM-BASED RESPONSE}

How might Tomlin respond to this modification? If benefit foisting really is justified in the case of childrearing, then it must be because the case of childrearing exhibits special features that do not apply in the case of Mountain Rescue II. Thus, in order to respond to the above argument, Tomlin must be able to identify a relevant difference between the two cases that can explain why benefit foisting is justified in one case but not the other, despite the fact that in both cases the benefactor is responsible for the beneficiary's need to be provided with an essential benefit. What could this difference be?

It is tempting to argue that the relevant difference between the two cases is that Alan has harmed the hikers by imperilling them, whereas parents do not harm, and perhaps even benefit, their children by bringing them into existence. Thus, there is a compensatory explanation for Alan's obligation to assume the cost of the rescue that does not apply in the case of parents, and which explains why the two cases ought to be treated differently from a moral point of view. This, in effect, is the strategy that Tomlin pursues by presenting Bart Harms Lisa/Bart Saves Lisa and conditioning his argument on our not believing that parents harm their children by creating them in such a way that they owe them compensation. Can this type of strategy succeed with respect to the more analogous case of Mountain Rescue II?

By appealing to the notion of harm to ground a relevant difference between the two cases, Tomlin is committing to a fourth condition for the permissibility of benefit foisting:

(1) the benefit in question is necessary for an acceptable life;

(2) the recipient is not available to provide their consent;

(3) it is not possible or reasonable for them to wait to become so available; and 
(4) the benefit is not provided in response to a harm that the benefactor has previously inflicted.

The question, then, is whether this fourth condition can explain why benefit foisting is permissible in the case of childrearing but not in the case of Mountain Rescue II.

If we understand harm in a counterfactual sense, according to which a person is harmed by an act when they are made worse off than they otherwise would have been, then condition (4) can draw a relevant distinction between the two cases: while the hikers are made worse off by being put in a position where they need to be rescued, children are not necessarily made worse off by being put in a position where they need to be raised. ${ }^{14}$ Moreover, condition (4) is also independently plausible as a condition for the permissibility of benefit foisting, as we would have strong reason to reject an account that permitted us to harm other people and then demand that they contribute toward the cost of rectifying that harm. Notice, however, that condition (4) only works as a response to the responsibility objection if Alan's having harmed the hikers is what explains why he is obligated to assume the cost of the rescue. This, however, is not obviously the case. An alternative but equally plausible explanation is that by imperilling the hikers, Alan has exposed them to a serious risk of harm, and thereby incurs an obligation to prevent that harm from occurring by conducting a rescue. On this explanation, what is relevant for the generation of the obligation is not that the hikers are made comparatively worse off from their pre-need to their post-need condition, but rather that they are put at risk of serious harm unless an essential need of theirs is met. Because Alan is responsible for the imposition of that risk, he bears the primary responsibility for mitigating it.

By parity of reasoning, even if parents do not make their children worse off by bringing them into existence, they nevertheless expose them to a serious risk of harm by doing so, and thereby incur an obligation to prevent that harm from occurring by providing them with an upbringing. If this is correct, then

\footnotetext{
${ }^{14}$ This could in principle be for one of two reasons: either (1) because the quality of their existence is not so bad as to make non-existence preferable; or (2) because no intelligible comparison can be made between non-existence and existence that would support the judgment that they have been made comparatively worse off. However, if Tomlin wants to suggest that children can benefit overall by being brought into existence, it seems like his argument must assume the former view. For a defense of the former view, see Feinberg (1992); for a defense of the latter view, see Heyd (1992).
} 
appealing to condition (4) is insufficient as a response to the responsibility objection, for we can account for the relevant obligation in a way that does not assume anyone has been made worse off.

One might respond that this is not the only way the notion of counterfactual harm can be understood. In addition to being made worse off from their pre-need $(t 1)$ to their post-need $(t 2)$ condition, the parties in either case might also be made worse off as a result of the entire exchange - that is, they might be made worse off from their pre-need condition $(t l)$ to the condition they occupy after their needs have been satisfied ( $t 3$ ) (see Table 1 below). If we understand the notion of harm in this second way, we might be able to draw a different distinction between the two cases. While the hikers might be worse off overall as a result of Alan's actions, children are not obviously worse off overall as a result of their parents' actions - in fact, they might even be considered better off insofar as they are happy to have been born and raised. If this is the case, we would then have alternative grounds for thinking that benefit foisting is justified in the case of childrearing but not in the case of Mountain Rescue II, for only in the case of childrearing is an overall benefit actually delivered.

$\begin{array}{cccc} & t 1 & t 2 & t 3 \\ \text { Hikers } & \text { Hiking } & \text { Imperilled } & \text { Rescued } \\ \text { Children } & \text { Non-existent } & \text { Created } & \text { Raised }\end{array}$

\section{Table 1: Two Points of Counterfactual Comparison}

Can this revised strategy succeed? I do not believe it can. If the presence of harm in this second sense is what explains why Alan's act of benefit foisting is impermissible, then this implies that it would be permissible in the absence of harm. However, removing the harmful element from the case of Mountain Rescue II does not strengthen the case for benefit foisting. Suppose that instead of being harmed by Alan's intervention, the hikers are made better off by it, for having jointly gone through what they perceived to be a neardeath experience, they have developed a closer sense of camaraderie and a deeper appreciation for life's 
benefits. Suppose further that Alan could reasonably foresee this outcome ahead of time, for being familiar with the psychological phenomenon of post-traumatic growth, he is aware that people sometimes respond to such experiences with positive changes in their attitudes and values. In this modified case, Alan would not owe the hikers compensation for having harmed them - he has all-things-considered benefitted them as a result of his intervention - though it is still implausible to claim they have a fairness-based obligation to share in the cost of the rescue. Indeed, because the benefit of a rescue was not in fact essential prior to Alan's imperilling them, the hikers are not in a morally different position than a recipient of Nozick's book tosser: while they might have reasons of gratitude to express their appreciation for the benefit they received, they do not have duties of justice to share in its costs. Similarly, even if children are benefitted overall as a result of being created and raised, this type of benefit again does not meet Tomlin's own criteria for permissible benefit foisting, as it is not in fact essential prior to a child's being brought into existence. Thus, as a response to the parental responsibility objection, the harm-based argument fails.

\section{CONCLUSION}

In order for Kids Pay to succeed, it must be true that a beneficiary can be liable to share in the cost of an essential benefit that the benefactor is responsible for her requiring. I have argued in this paper that this claim is generally false and particularly suspect in the kinds of cases that Tomlin needs it to be true, namely, cases in which a benefactor has created the need to be benefitted to satisfy as self-regarding interest in providing the benefit. Thus, insofar as parents (a) electively put their children into a needy state for the purpose of (b) satisfying a self-regarding interest in meeting their children's needs, they lack a legitimate fairness-based against their children to share in its associated costs. One modest conclusion that can drawn from these remarks is that if the principle of fair play is to be invoked as a basis for sharing the costs of childrearing, it is more plausibly invoked with respect to benefits that non-parents can be understood to voluntarily accept (cf. Lotz, 2017, pp. 119-126), including the social security benefits they will enjoy in old age. 


\section{REFERENCES}

Alstott A (2004) No Exit: What Parents Owe Their Children and What Society Owes Parents. Oxford: Oxford University Press.

Arneson R (1982) The Principle of Fairness and Free Rider Problems. Ethics 92(4): 616-633

Bou-Habib P (2013) Parental Subsidies: The Argument from Insurance. Polit Philos Econ 12(2):197-216

Casal P (1999) Environmentalism, Procreation, and the Principle of Fairness. Public Aff Q 13(4): $363-$ 376

Casal P, Williams A (2004) Equality of Resources and Procreative Justice. In: Burley J (ed) Dworkin and His Critics. Malden, Mass.: Blackwell

Clayton M (2006) Justice and Legitimacy in Upbringing. Oxford: Oxford University Press

Feinberg J (1992) Wrongful Life and the Counterfactual Element in Harming. In: Freedom and Fulfillment: Philosophical Essays. Princeton: Princeton University Press

Folbre N (2001) The Invisible Heart. New York: New Press

George R (1987) Who Should Bear the Costs of Children? Public Aff Q 1(1): 1-42

Hart HLA (1955) Are There Any Natural Rights? Philos Rev 64(2):175-19

Heyd D (1992) Genethics: Moral Issues in the Creation of People. Berkeley: University of California Press

Klosko G (1987) Presumptive Benefit, Fairness, and Political Obligation. Philos Public Aff 16(3): 241259

Liverpool Victoria (2015) The Cost of Raising a Child. https://www.lv.com/assets/life/pdfs/life-insurance/coac- 2015-infographic-compressed.pdf Accessed 20 October 2017

Lotz M (2017) Liberalism and the Status of Family-Making. In: Ahlberg J and Cholbi M (eds) Procreation, Parenthood, and Educational Rights. New York: Routledge.

McDermott D (2004) Fair Play Obligations. Polit Stud 52(2): 216-232

Nozick R (1974) Anarchy, State, and Utopia. New York: Basic Books.

Olsaretti S (2013) Children as Public Goods? Philos Public Aff 41(3): 226-258

Olsaretti S (2009) Responsibility and the Consequences of Choice. Proceedings of the Aristotelian Society 109: $165-188$

Rakowski E (1991) Equal Justice. Oxford: Oxford University Press

Rawls J. (1971) A Theory of Justice. Cambridge, MA: Harvard University Press 
Scheffler S (2013) Death and the Afterlife (ed) Niko Kolodny. Oxford: Oxford University Press

Shiffrin S (1999) Wrongful Life, Procreative Responsibility, and the Significance of Harm. Leg Theory 5: 117-148

Simmons, AJ (1979) The Principle of Fair Play. Philos Public Aff 8(4): 307-337

Tomlin P (2015) Should Kids Pay Their Own Way? Polit Stud 63(3): 663-678.

Vallentyne P (2002) Equality and the Duties of Procreators. In: Archard D and Macleod CM (eds) The Moral and Political Status of Children. Oxford: Oxford University Press. 